\title{
MUNDIALIZAÇÃO, INDIVIDUALISMO E MOVIMENTOS SOCIAIS: CONSTRUÇÃO DA CIDADANIA PLANETÁRIA?
}

\author{
Paulo Ricardo Bavaresco ${ }^{l}$ \\ Giovana Maria Di Domenico Silva ${ }^{2}$
}

\begin{abstract}
RESUMO: O presente trabalho objetiva verificar a possibilidade da construção do exercício da cidadania planetária. Durante os últimos anos, os avanços tecnológicos transformaram de tal forma a sociedade, possibilitando, assim, o surgimento de movimentos sociais globais. A partir desses movimentos, reivindicações de caráter local passaram a ser globais, pelo fato da instantaneidade das comunicações que os conecta, em tempo real, com outros movimentos mundiais. Ao mesmo tempo em que a tecnologia das comunicações ampliou as relações entre os movimentos sociais e encurtou distância promoveu também a individualização da sociedade. Porém, essa individualização, marco da atualidade, torna-se um verdadeiro entrave na construção de direitos globais. Destaca-se que, embutido nessa realidade, o indivíduo parece estar mais preocupado com seus direitos pessoais do que com os direitos de uma categoria, enfim os direitos coletivos. E mais, na sociedade atual, o indivíduo procura viver o presente, no entanto, a construção da cidadania planetária é o desafio para o futuro.
\end{abstract}

Palavras-Chave: Indivíduo. Movimentos Sociais. Cidadania Planetária.

\section{GLOBALIZATION, INDIVIDUALISM AND SOCIAL MOVEMENTS: CONSTRUCTION OF PLANETARY CITIZENSHIP?}

\begin{abstract}
This work purposes to verify the possibility of construction of planetary citizenship. During the recent years the technological advances have transformed such a society, thus enabling the emergence of global social movements. From these movements claims of local character have become global, because instantaneous communications that connects in real time with other worldwide movements. At the same time that communications technology has expanded the relationship between social movements and shortened distance also promoted the society's individualization. However this individualization, today's mark, it becomes a real obstacle to build global rights. It is noteworthy that embedded in this reality, the individual seems to be more concerned about their personal rights than the rights of a category, and finally the collective rights. Plus the fact that, in today's society, the individual seeks to live the present, however, the construction of global planetary citizenship is the challenge for the future.
\end{abstract}

Key-words: Individual. Technology. Social Movements. Planetary Citizenship. Democracy

\section{INÍCIO DE DISCUSSÃO}

\footnotetext{
1 Professor e pesquisador na Universidade do Oeste de Santa Catarina - UNOESC. Contato: paulo.bavaresco@unoesc.edu.br
} 
A sociedade passa por mudanças significativas, na atualidade, devido à rapidez das tecnologias e a facilidade de acesso a um grande número de indivíduos da sociedade. Aparelhos de comunicação sofisticados, sinais por satélites e televisão a cabo levam informações ao vivo, a todo instante, aos mais distantes locais do planeta. A revolução das telecomunicações aproximou mercados e ampliou o fluxo do capital de uma forma jamais vista anteriormente. As relações políticas dos Estados Nacionais sofreram alterações a ponto de levantar suspeita sobre a possibilidade de um governo universal. Nas relações sociais, a individualização rompe com as relações de solidariedade e com o coletivismo antes existente. Todas essas modificações que ocorrem em nível mundial e que são presenciadas, hoje, resultam, em primeiro lugar, dos avanços tecnológicos. Alguns teóricos associam e defendem que isso é resultado do processo de globalização. Outros, porém, acreditam que reduzir todas essas alterações provocadas na sociedade, à palavra globalização, é muito generalizado.

A globalização, para Giddens (2005, p. 41), “[...] não diz respeito em absoluto apenas, ou mesmo basicamente, à interdependência econômica, mas à transformação do tempo e do espaço em nossas vidas". A compressão do espaço e tempo, em parte, é proveniente do processo tecnológico que aproximou as nações e encurtou o tempo dos transportes, de deslocamentos de pessoas e capital e, também, da comunicação. Para Bourdieu (2002, p.13): "Globalização é um mito, um instrumento de combate ideológico muito forte e funcional para os dominantes na luta contra as conquistas sociais". De fato, o imperialismo cultural e econômico das nações ricas se impõe sobre as demais sociedades disfarçadas na lógica de mercado. Sobre esse aspecto, far-se-á uma discussão na primeira parte desse trabalho.

Em segundo lugar, a individualização da sociedade tem como principal causador o próprio agente tecnológico. A rapidez com que se deve dar respostas às atividades diárias, aliada à precisão dessas respostas, a própria vida cotidiana, nos centros urbanos, o consumo desenfreado e a autorrealização são consequências das armadilhas que a sociedade de consumo e de alta tecnologia prega.

Há um fator importante, nesse contexto, embora ocorra a individualização das sociedades, os movimentos sociais, na atualidade, têm mostrado que as lutas sociais passam a ser globais. Salienta-se que esse aspecto será tratado na terceira parte, procurando observar os pontos positivos e negativos desses novos movimentos sociais. Assim, a discussão que se apresenta aqui tem como objetivo analisar os movimentos sociais, redes de movimentos

2 Professora e pesquisadora na Universidade do Oeste de Santa Catarina - UNOESC. Contato: giovana.silva@unoesc.edu.br 
sociais, movimentos ambientalistas e ONGs - Organizações Não Governamentais -, na atualidade.

De início, uma questão se coloca: Esses novos movimentos sociais têm um viés capaz de desenvolver uma cidadania planetária? A princípio, as questões ambientais e os movimentos em defesa da preservação ambiental procuram buscar a conscientização da humanidade para os problemas dessa ordem. Do mesmo modo, a democracia parece se estender e se concretizar dentro desses novos movimentos sociais. No entanto, o caminho para a construção da democracia parece ter apenas começado.

\section{GLOBALIZAÇÃO}

O termo globalização ocupou posição central, nos debates acadêmicos, e torna-se comum explicar as mudanças que ocorrem, nos últimos anos, pelo viés do termo. Entende-se por globalização os processos atuantes numa escala global, que atravessam fronteiras, conectando e integrando comunidades e organizações em novas relações de espaço-tempo. A rapidez das comunicações, a aceleração das inovações tecnológicas, as novas formas de intervenção do Estado, o aumento da disparidade econômica e social entre os países são as principais características que levam a perceber o processo em andamento.

O processo de globalização não é tão atual como pensam alguns. Ele remete a outros povos mais antigos, os quais já haviam iniciado a integração econômica e social. Retornando à história das sociedades, verifica-se que o processo atual que perpassa os países teve seu início em tempos passados. Certo que, de forma mais lenta, devido às dificuldades de comunicações e a lentidão nos transportes. No entanto, foi a tecnologia que colocou esses países mais próximos, atualmente, aumentando a integração entre eles.

Para Anthony Giddens (2005, p.40), a globalização é algo novo:

A globalização econômica, portanto, é uma realidade, e não se trata apenas de uma continuação de tendências de anos anteriores ou de uma reversão a elas. Embora uma parte considerável do comércio permaneça regionalizada, há uma "economia plenamente global" no nível dos mercados financeiros.

Os Egípcios, há 3000 a.C., já comerciavam com diversos povos da Ásia. Também os Fenícios conheciam muito bem os mares e desenvolveram ótimas técnicas de navegação para aquela época. Dominaram os mares e tornaram-se grandes comerciantes. Esse comércio 
contribuiu muito para a troca de tecnologia e modos culturais entre os povos antigos. Também os povos da América, na Antiguidade, mantinham fortes relações comerciais e de troca entre si. Mesmo que não houvesse dependência de produção entre um e outro, esses laços de comércio ampliavam a troca de experiências tecnológicas e culturais.

Com a chegada dos europeus na América, no século XV, teve-se um impulso maior na aproximação dos povos. A cultura trazida pelos europeus, imposta sobre o povo americano, é mesclada com os hábitos culturais dos habitantes do novo mundo. $\mathrm{O}$ modo brutal e arcaico como a cultura europeia foi disseminada, na América, sob a liderança do capital emergente da época, e, ainda, sob forte influência da Igreja, não difere muito do processo que está em andamento, na atualidade, que é a propagação e domínio da cultura ocidental sobre os demais povos.

No entanto, a colonização e exploração de todos os recantos do planeta, e a divulgação da cultura ocidental, principalmente aquela voltada para a difusão da cultura econômica, ocorriam, ora de forma mais lenta, ora mais rápida, devido às crises cíclicas do capitalismo. Pode-se perceber que, durante a Primeira Guerra Mundial, a crise de 1929 e a Segunda Guerra Mundial, criaram-se forte sentimento nacionalista em todos os países, levando-os a um recuo na comercialização em nível mundial. Passados esses períodos e com a desintegração do bloco socialista, o processo volta com maior rapidez. O fluxo de capitais, tecnologia, a difusão cultural e o domínio das empresas multinacionais fogem do controle dos Estados, levando estes a buscarem novas formas de intervenção.

Assim, a rapidez com que os meios de comunicações anunciam as mudanças e os acontecimentos globais, leva grande parte da população a um sentimento de incapacidade frente às inovações tecnológicas. Esse avanço tecnológico que surge após a Segunda Guerra Mundial é aplicado, principalmente, ao setor econômico, tornando o mundo um círculo de transações comerciais e de transferência de capitais que acontecem de forma muito rápida. Essas mudanças, além de criarem, na maioria das sociedades que formam o conjunto de países pobres, o desconforto e o sentimento de inferioridade, criam novos excluídos no processo global: os dependentes tecnológicos.

A revolução das comunicações e a difusão da tecnologia de informação estão profundamente ligadas a processos de globalização. Isso ocorre mesmo na arena econômica. Mercados financeiros que operam 24 horas por dia dependem de uma fusão de tecnologia de satélite e computador, afetando muito outros aspectos da sociedade também. Um mundo de comunicação eletrônica instantânea, em que 
até aqueles nas regiões mais pobres estão envolvidos, perturba instituições locais e padrões de cotidiano de vida. (GIDDENS, 2005, p. 41).

O que se vive, atualmente, é uma rapidez maior nas transferências de capitais e mercadorias entre os países. A teia de relações possui ramificações por todos os recantos, produz e reproduz o sistema econômico capitalista por meio da transferência cultural e tecnológica. Isso nada mais é que o novo modo de domínio econômico, aumentando ainda mais a transferência de capitais para as nações mais ricas.

A globalização é, pois, um mito e tem no seu interior algumas justificativas que são formas distorcidas da teoria econômica. Em primeiro lugar, alerta que "a economia é um domínio à parte, separado do mundo social, governado por leis naturais, universais, que os governos não devem contrariar”. (BOURDIEU, 2002, p. 12). Nesse aspecto, a globalização é uma ordem imposta e que todos os países devem aceitar.

[...] o mercado é a instância capaz de organizar de forma ótima as relações sociais, as trocas, a produção, etc. e também garantir a distribuição eqüitativa. Faz-se uma equação entre mercado e democracia. O terceiro postulado afirma que a globalização exige a redução das despesas do Estado, a diminuição das despesas sociais - ou seja, o retorno do laissez-faire - e a supressão de tudo que possa turvar a lógica pura do mercado. [...] a também todo um discurso segundo o qual o welfare state [estado do bem-estar social] estimula a preguiça, velho discurso americano ligado à tradição calvinista do self-help [se virar por conta própria]. (BOURDIEU 2002, p. 12).

De fato, a imposição ao mundo do processo de globalização vem fundamentada nos discursos de uma economia pura e universal. Esses mecanismos econômicos são difundidos por grupos nos quais circulam valores econômicos altíssimos. Isso também ocorre por meio do imperialismo cultural e pelas grandes corporações nas quais as atividades estão relacionadas com a desregulamentação.

Destaca-se que junto ao processo de desregulamentação vem o programa neoliberal e as privatizações. Nesse aspecto, assistimos à passagem do público para o privado, da escola e da saúde pública para a privada. As empresas estatais mais rentáveis passaram para empresas privadas, como é o caso da energia e da telefonia.

Um aspecto que chama atenção é que as desigualdades cresceram ainda mais, e a concentração de renda aumentou. Isso demonstra que o fator tecnológico é que impulsiona as relações mundiais hoje. A Globalização é apenas um disfarce da reorganização do capital 
mundial que passa a atuar em redes, fixando-se ora aqui, ora ali, com rapidez enorme que somente é possível via comunicações com alta tecnologia.

\section{INDIVIDUALISMO}

O Neoliberalismo e a possibilidade da tecnologia, hoje, têm contribuído, de forma significativa, na individualização da sociedade. Sobre esse aspecto é preciso revisar as transformações que foram provocadas pela tecnologia na sociedade atual. Essas transformações passam também pelas questões institucionais. Nesse sentido, é possível destacar a ruptura dos laços sociais, principalmente, em instituições como a família, a escola e os movimentos sociais. Os meios tecnológicos, a mídia, as comunicações, o consumo irracional de produtos supérfluos, entre outros têm contribuído para o surgimento de uma sociedade individualizada.

Destaca-se que há divergências entre o individualismo provocado pelas alterações sociais, no mundo de hoje, e o individualismo associado às tradições e aos costumes. Segundo Giddens (2005, p. 46):

\footnotetext{
Em vez de ver nossa época como marcada pela decadência moral, portanto, faz sentido vê-la como uma época de transição moral. Se o individualismo institucional não é sinônimo de interesse pessoal, ele representa uma ameaça menor para a solidariedade social, mas implica que devemos buscar novos meios para produzir essa solidariedade.
}

As mudanças sociais provocados pelo neoliberalismo, ou pelos arranjos do mercado afetam todos os indivíduos e, na verdade, privatizam a sociedade. $\mathrm{O}$ recuo do Estado e a política neoliberal privatizam religião, educação, saúde, etc., e a sociedade de mercado se impõe sobre tudo. Até mesmo o comportamento dos indivíduos sofre e se delineia no meio das relações do mercado, como, por exemplo, o consumo anônimo. Esse consumo pode ser analisado pelo viés da tecnologia, quando o mercado de telefonia móvel cresceu assustadoramente, nos últimos anos, no Brasil.

Instalaram-se sociedades reestruturadas pela lógica e pela própria temporalidade da moda; em outras palavras, um presente que substitui a ação coletiva pelas felicidades privadas, a tradição pelo movimento, as esperanças do futuro pelo êxtase do presente sempre novo. [...] consumir sem esperar; viajar; divertir-se; não renunciar a nada: as políticas do futuro foram sucedidas pelo consumo como promessa de um futuro eufórico. (LIPOVETSKY, 2004, p. 60-61) 
O consumo está associado à busca de algo que dará prestígio e reconhecimento ao indivíduo na sociedade. É por meio do consumo que os indivíduos buscam construir uma imagem própria de si. Essa imagem é exigida, justamente, porque se está em um mundo de mudanças muito rápidas, promovidas pelos avanços tecnológicos galopantes.

É por meio do consumo tipo maníaco que o indivíduo cria vínculos de pertencimento a determinados grupos, ou mesmo pertencimento à sociedade. Sobre esse aspecto, Martha N. Ruiz (2006, p. 50) diz que o consumo não é uma satisfação para si mesmo, "mas una compulsión de tipo maníaco: tengo que tenerlo, no importa que tenga cien, no importa que no tenga un centavo en el banco, no importa que me quede sin comer. Tengo que tenerlo".

Não se trata somente de consumo de objetos, mas também o consumo de serviços e de valores que passam a ser construídos no centro da sociedade de consumo. A internet, com milhões de páginas e sites, é um grande atrativo de entretenimento, pois contém jogos e diversões. É, também, um espaço de erotismo e sexualidade vendido a bilhões de internautas sem limite de idade. Da mesma forma, os shoppings centers que se tornaram verdadeiros templos de consumo.

Fora isso, o consumo também tem se destacado em produtos de saúde, beleza e aparência para o corpo humano. Nunca a humanidade consumiu tantos produtos para manter a aparência e ver-se melhor. São vitaminas para combater todos os tipos de males, alimentos que trazem mais saúde e inúmeros produtos para pele, cabelo, unhas, entre outros.

[...] Vitamina $\mathrm{C}$ para evitar resfriados, vitamina $\mathrm{E}$ para una piel hermosa, vitamina $\mathrm{B}$ para el cérebro, ginko biloba para espantar el alzheimer, ácido alfalipóico para prolongar elivino tesouro de la juventud, ácido clorhídrico para la digestão, aceites omega 3 para combatir el colesterol, y para la inteligência. (RUIZ, 2006, p. 52)

Mas o que tudo isso tem a ver com a individualização da sociedade? Isso demonstra a angústia, a insatisfação e as exigências que marcam este tempo. Sinônimo de desencantamento com o coletivo e ligado à individualização das condições de vida, representa o verdadeiro culto às felicidades individuais. Alain Touraine (2002) chama a atenção para a decadência e o desaparecimento do universo social, ou seja, a ruptura nas instituições sociais como a família, a escola, inclusive os movimentos sociais. Essa ruptura é possível de detectar, principalmente, se olharmos para a construção da identidade relacionada com a tecnologia. A nova geração, a geração da internet, mantém relações interpessoais a distância, encontrando 
respostas rápidas às suas dúvidas. Respostas que já não mais encontram e não buscam no âmbito familiar.

Martha Ruiz (2006, p. 66) afirma: "Cuando los adolescentes de mi geración o de la anterior tenian alguna duda, solían acercarse a sus padres para perguntar [...] porque se valoraba la experiência". Hoje, a experiência dos velhos foi trocada pela máquina, pela tecnologia. Aqui, destaca-se, embora seja apenas um exemplo, a ruptura dos laços familiares. A família passa a ser, simplesmente, a provedora de capital para que os filhos possam desfrutar do alto consumo na sociedade atual.

A escola, instituição que também sofre as rupturas provocadas pela tecnologia, já não atende aos interesses da sociedade, nem mesmo do capital. O sistema escolar depende muito mais de doações e caridades para manter o funcionamento do que os investimentos estatais. $\mathrm{O}$ ensino passa a ser comércio, dentro de um mundo que é movido pelo econômico e pelo tecnológico. Assim, privatiza-se o ensino, e a busca pelo conhecimento é menor e maior se torna o interesse pelo diploma. Gilles Lipovetsky (2004), que chama essa sociedade de hipermoderna destaca que:

A cultura hipermoderna se caracteriza pelo enfraquecimento do poder regulador das instituições coletivas e pela autonomização correlativa dos atores sociais em face das imposições de grupo, sejam família, sejam da religião, sejam dos partidos políticos, sejam das culturas de classe. (LIPOVETSKY, 2004, p. 83).

Quanto aos movimentos sociais, também nestes é possível notar significativa mudança. As lutas dos trabalhadores e operários que reivindicavam melhores salários e condições de vida são substituídas por outros tipos de movimentos sociais. A cultura de classes desaparece e as lutas, antes centralizadas e focadas em sindicatos e partidos políticos, passam agora e ser mundiais. Nesse sentido, o pertencimento a uma classe social não existe mais. O indivíduo se identifica com vários grupos sociais com os quais encontra certa proximidade, ora em defesa ao meio ambiente, ora em defesa dos seus direitos pessoais, ora contra o racismo e assim por diante. Isso mostra a decadência das lutas de classe nas quais o indivíduo se sentia ligado pelo seu sindicato ou pela sua condição social.

Salienta-se, ainda, que a individualização da sociedade aumenta à medida que enfraquecem as instituições coletivas. E a dinâmica da individualização cresce e multiplica-se tanto quanto aumentam as possibilidades de mais e mais pessoas terem acesso aos meios tecnológicos. Se antes as classes sociais encontravam diferenças entre uma e outra (primeira, segunda e terceira classe), isso ocorria porque a primeira classe tinha condições de consumo 
maior que a segunda e terceira classes. Hoje, em uma sociedade massificada, diante do consumo de produtos que antes era restrito a alguns, torna-se difícil e quase não é mais possível sugerir que existe uma divisão de classes sociais. Destaca-se, nesse contexto, que o desemprego não é uma condição somente para alguns, mas ele ronda todos os indivíduos.

\section{MOVIMENTOS SOCIAS E A CONSTRUÇÃO DA CIDADANIA GLOBAL}

A sociedade que se tem, hoje, é fruto de avanços tecnológicos e estes repercutem em todas as direções. Assim como a sociedade está em constantes transformações, também os movimentos sociais têm características e aspectos diferentes dos movimentos e lutas sociais anteriores. Entre essas características está o poder de as lutas locais se tornarem globais pela força e difusão dos meios de comunicação. Na tentativa de superar os conflitos na sociedade atual, sejam eles ambientais, por emprego e renda, entre outros, os movimentos buscam novas formas de organização, as chamadas redes de movimentos sociais. (SCHERER-WARREN, 1993).

Não se pode negar, portanto, que os avanços tecnológicos têm facilitado as comunicações entre as diversas partes do mundo. Ampliando a troca de informações políticoeconômica criando, ainda mais, condições para a desterritorialização e transnacionalização da cultura. Ilse Scherer-Warren destaca que a telemática

[...] têm facilitado a comunicação e a troca de informações entre atores, trazendo para o cenário político práticas sobre a forma de redes e movimentos, que se caracterizam pela rapidez e abrangência espacial de suas manifestações (SCHERERWARREN, 1999, p 67).

Nesse sistema, todos os participantes que integram uma ação coletiva agem como atores, devido à participação ser livre e consciente. Naturalmente, os integrantes devem compartilhar de princípios comuns, como combate à miséria, exploração, desigualdade, violência, etc. Assim, cada movimento, individual ou coletivo, passa a se articular com outros movimentos.

Os movimentos feministas que surgiram durante os anos 60, junto com os movimentos estudantis, suspeitavam de todas as formas burocráticas de organização. Ainda que esses movimentos apelassem por uma identidade própria, passaram a atrair forças de outras organizações, ampliando, por vezes, o leque de reivindicações. Além da sua participação nas lutas emancipatórias, outras conquistas foram surgindo e abolindo a opressão do homem sobre 
a mulher, bem como na quebra de estereótipos sexuais. Mesmo que continuassem na luta em defesa da mulher, esses movimentos colaboraram também nas lutas em favor dos negros, crianças, deficientes, geração de emprego e renda, moradia, saúde, terra, enfim, passaram a fortalecer toda a rede de reivindicações.

É importante acrescentar que os movimentos em redes, que se formaram nos últimos tempos, apresentam características bastante comuns. Mas um aspecto que chama atenção é a transnacionalidade, principalmente os movimentos ecológicos e aqueles relacionados aos direitos humanos que, na verdade, são os movimentos mais estimulados nos últimos tempos. Esses formam, quando conectados com movimentos populares, grandes redes de pressão internacional.

Nessa estrutura, ao que tudo indica, os integrantes se ligam horizontalmente a todos os demais, diretamente ou por meio dos que os cercam. O resultado é como uma malha de múltiplos fios que se espalha por todos os lados. Nenhum dos seus nós é considerado o principal ou central, muito menos representante dos demais. Não existe, portanto, um único representante ou líder, o que existe é a vontade coletiva de alcançar determinado objetivo. Segundo Ilse Scherer-Warren (1999, p. 72):

\footnotetext{
As redes, seja de informação, seja de intercâmbio temático, ou para pressão nos campos simbólicos e políticos, caracterizam-se por seus novos formatos organizacionais, em que as relações sociais são mais horizontalizadas, complementares e, portanto, mais abertas ao pluralismo e à diversidade cultural.
}

As redes de movimentos sociais têm uma característica importante que é a questão democrática. E, juntamente, com o papel democrático exercem e fomentam lutas por uma sociedade justa e igualitária.

A classificação e a representação desses movimentos sociais, de acordo com Ilse Scherer-Warren (1999), podem ser assim relacionadas:

- $\quad$ ONGs - Organizações não governamentais - organismos privados, sem fins lucrativos, com participação voluntária. Trabalham para fins públicos.

- $\quad$ OIGs - Organizações intergovernamentais - surgem de acordos entre EstadosNações e estão abertas à participação de organizações da sociedade civil.

- $\quad$ MECs - Movimentos ecologistas comunitários - formam-se a partir das mais diversas organizações de bases, associação de bairro, de rua, de moradores, locais e outros. Defendem um problema socioambiental local. 
- MENs - Movimentos ecologistas nacionais - articulam-se entre ONGs, movimentos ambientalistas e cidadãos, quando em escala nacional.

- $\quad$ METs - Movimentos ecologistas transnacionais - organizam-se em redes transnacionais que se mobilizam em torno de uma tragédia ou problemas ambientais que requerem ações imediatas.

As novas tecnologias modificaram as relações de espaço e tempo e trouxeram maior avidez ao capital mundial. Da mesma forma, contribuíram para a individualização da sociedade. Por outro lado, modificaram os movimentos sociais que agora atuam em redes e por meio da possibilidade de trocas mais rápidas de informações, passando a adquirir articulações mundiais. Diante disso, a pergunta que vem à tona é: Há a possibilidade dos movimentos sociais que agem em nível mundial promoverem a construção de uma cidadania planetária?

Quando se associa a construção de valores universais aos movimentos sociais, é notável o destaque para a democracia. O debate sobre a democracia não é recente e, à medida que novos indivíduos passam a exigir o exercício democrático, tende a aumentar. É certo que se pode construí-la, como valor universal e como forma de gerir assuntos humanitários; é a melhor forma até agora encontrada. No entanto, como valor universal, de que forma se pode justificar a guerra com outras sociedades em nome da democracia? Alguns países, atualmente, sofrem embargos econômicos, são excluídos dos debates internacionais e recebem interferência direta, de forma violenta, por países que se dizem democráticos.

Nesse caso, a construção de uma cidadania planetária não pode violar os direitos humanos, ou melhor, o direito à vida. Que poder é dado às grandes potências mundiais para definirem que os países devem ser democráticos? Que o projeto de política neoliberal é a melhor saída para os países periféricos? Esse questionamento pode ser avaliado por meio dos escritos de Bourdieu (2002, p. 14):

De um lado, temos o FMI, que enfraquece os Estados (que, às vezes, mal se construíra), impõe restrições orçamentárias, joga na rua os desempregados [...] paralelamente, ocorre o desenvolvimento de organizações humanitárias, de ONGs que suplementam o Estado, preenchem funções que anteriormente pertenciam ao Estado, à mão esquerda do Estado. A escola, a saúde e a educação passam a depender cada vez mais de instituições humanitárias não-governamentais menos independente do que os Estados em relação às forças econômicas mundiais, às intermitências de suas generosidades e às flutuações de suas políticas. 
O FMI - Fundo Monetário Internacional - tem sido muito prestativo e próximo de ONGs que estão ao seu lado. Também, no decorrer dos últimos anos, algumas Organizações Internacionais passaram a ser fiscalizadas e orientadas pelo FMI. Riccardo Petrella (2002, p. 92) alerta que:

No decorrer dos últimos vinte anos, os programas de ação das instituições políticas intergovernamentais que, para melhor ou para pior, prometiam algum tipo de cooperação e solidariedade, foram ficando cada vez mais marginalizadas. Não são mais a Unesco, a Organização Mundial da Saúde e a Organização de Alimentos e Agricultura (Fao) ou a organização Internacional do Trabalho que orientam e gerenciam a busca de soluções para os problemas do mundo; essas tarefas agora recaem sobe as agências financeiras internacionais, o Banco Mundial e o FMI.

À medida que surgem novos movimentos que criam e reforçam instituições e organizações em defesa de questões ligadas à humanidade, as organizações mundiais, já institucionalizadas, perdem força frente ao capital mundial. Os financiamentos do Banco Mundial para grandes corporações, das quais pretende tirar enormes vantagens econômicas, direcionam-se, também, para o mercado da água, tendo perspectivas de que a comercialização da água, num futuro bem próximo, será de trilhões de dólares. "Depois do colapso das ações das empresas de tecnologia, a revista "fortune" identificou o negócio da água como a indústria mais lucrativa para os investidores" (FORTUNE MAGAZZINE, 2002. apud SHIVA, 2006, p. 107). Destaca-se, aqui, que grandes empresas cobiçam esse mercado, entre elas a Monsanto que possui grandes investimentos em negócios de biotecnologia agrícola.

Existem inúmeras ONGs espalhadas pelo mundo que buscam preservar a água como propriedade da humanidade. No entanto, a privatização da água já se faz notar por diversas empresas. Até que ponto as ONGs poderão lutar na defesa da água como um bem comum? Vandana Shiva (2006), em seu trabalho Guerras por Água, traz um recorte de um documento da Monsanto intitulado Watter Business Plan, documento inédito, 1998, que diz:

Em 2000, o negócio de fornecimento de água potável foi estimado em trezentos milhões de dólares na Índia e no México. Esta é a quantia atualmente gasta pelas organizações não-governamentais (ONGs) em projetos de desenvolvimento e esquemas de fornecimento de água por parte dos governos locais; a Monsanto espera drenar esses recursos públicos para fornecer água às comunidades rurais. Onde os pobres não puderem pagar, a empresa planeja criar "mecanismos não tradicionais, direcionados a construir relacionamentos com os governos locais e as ONGs, assim como construí-los por meio de mecanismos inovadores de financiamento, como microcrédito. (MONSANTO, 1998. apud SHIVA, 2006, p. 108). 
As ONGs - Organizações Não Governamentais - , nesse caso, servem para organizar projetos que, mais tarde, serão financiados ou terão a "ajuda" e/ou o controle pelas grandes empresas que veem os vantajosos lucros desses potenciais. O Banco Mundial tem liberado financiamentos para inúmeras ONGs, porém são destinados a projetos que futuramente possam dar retorno financeiro ao grande capital. Enquanto isso, projetos sociais desenvolvidos em bairros ou nas periferias dos grandes centros, também financiados com recursos do Banco Mundial, servem como rótulo que esconde os investimentos em ONGs que atendem aos interesses do capital mundial.

O que ocorre, nesse contexto, é que nem o capital e nem mesmo as ONGs podem substituir os governos. Não é possível que se restaure o Estado como de outros tempos (autoritário, burocrático, conservador), mas também não se pode permitir que o Estado se retire completamente e seja substituído pelo mercado e pelas ONGs.

Muitos movimentos sociais surgiram à medida que questões ambientais passaram a ser localizadas. Nesse aspecto, indivíduos passaram a ver a problemática local em conjunto com lutas globais. A questão energética, por exemplo, sugeriu da construção de pequenas e médias hidroelétricas no Brasil. A construção de barragens supõe resolver o problema de energia, no entanto, outra situação surge: os atingidos pelas barragens.

Esses movimentos estão relacionados com uma questão global que é a Água. A mesma água que produzirá energia vai desabrigar inúmeras famílias que perdem a terra produtiva, o lar e a identidade de pertencimento àquele local. Agora, uma vez atendidas as reivindicações desses movimentos (que será uma nova área para viver), essas famílias ainda estarão na luta pela questão da água? Talvez sim, caso não tenham acesso à água potável, mas é bem provável que atendida essa demanda, o movimento tende a cessar.

Em relação aos movimentos sociais, o indivíduo participa em diferentes lutas e frentes de demandas, pelos seus direitos. Nessa sociedade de risco, globalizada (GIDDENS, 2005), em que os movimentos atuam em redes (SCHERER-WARREN, 1999), o indivíduo, depois de conquistado a(s) sua(s) reivindicações, continuará lutando pelos direitos coletivos? Torna-se difícil uma resposta que se aproxime desse questionamento. No entanto, hoje, os indivíduos estão mais preocupados com o seu eu, como foi possível ver. A sociedade hipermoderna (LIPOVETSKY, 2004) e a sociedade do hiperconsumo (RUIZ, 2006) têm preocupação em viver o presente, mas construir uma cidadania planetária é um grande desafio para o futuro.

\section{ALGUMAS CONSIDERAÇÕES}


O avanço tecnológico provocou um encurtamento do espaço, dando possibilidades de conhecer outros povos e outras culturas. No entanto, o relativismo cultural ainda se faz presente na sociedade da tecnologia. É indispensável salientar, que a tecnologia não foi capaz de reduzir as desigualdades sociais, antes fez aumentar e, ao mesmo tempo, provocou a migração em massa de pessoas para outras regiões, principalmente para os países ricos, onde a xenofobia é causa de atritos e manifestações violentas.

Embora os movimentos atuais se articulem em redes, e as informações circulem com maior rapidez, o individualismo não pode deixar de ser visto como entrave nessas lutas. As questões ambientais do planeta estão, portanto, abaladas e existem previsões de que a humanidade poderá ainda existir por somente cem anos, caso o consumo se mantenha nesse patamar. Viver o presente, princípio dos indivíduos, hoje, é um desafio para o desenvolvimento com sustentabilidade que supõe: viver bem hoje e deixar condições de vida melhor para as próximas gerações.

O consumo compulsivo, maníaco, exige recursos ambientais cada vez maiores, frente às paranóias dos indivíduos que consomem representações simbólicas em uma sociedade de mudanças cada vez mais rápidas. Esses recursos do planeta são limitados, mas a mentalidade de consumo, de hiperconsumo dos indivíduos que procuram construir laços de pertencimento a esse universo parece que os tornam quase que irracionais.

Portanto, para falar da construção da cidadania planetária é preciso acompanhar as práticas dos diferentes movimentos sociais que lutam pelas questões ambientais, pelo fim da opressão, bem como aqueles pequenos movimentos de rua, de bairro, de donas de casa, enfim, movimentos que se articulam em defesa da liberdade. Na verdade, a construção de direitos universais passa, primeiramente, pela liberdade. Também é possível apostar na construção da democracia como valor moral universal. No entanto, a democracia e a liberdade não podem ser levadas aos demais povos, aos moldes como sugere o capital mundial, nem mesmo pela força dos países que se dizem democráticos e procuram construir direitos universais que representem os seus interesses.

\section{REFERÊNCIAS}

BOURDIEU, Pierre. Pierre Bourdieu entrevistado por Maria Aparecida Loyola. Rio de Janeiro: Ed. UERJ, 2002.

GIDDENS, Anthony. A Terceira Via: reflexões sobre o impasse político atual e o futuro da social-democracia. 5. ed. Rio de Janeiro: Record, 2005.

SCHERER-WARREN, Ilse. Redes de Movimentos Sociais. São Paulo: Loyola, 1993. 
Cidadania sem fronteiras: ações coletivas na era da globalização. São Paulo: Hucitec, 1999.

LIPOVETSKY, Gilles. Os tempos hipermodernos. São Paulo: Barcarolla, 2004.

PETRELlA, Riccardo. O Manifesto da Água. Argumento para um contrato mundial. Petrópolis: Vozes, 2002.

RUIZ, Martha Nélida. El Espejo Intoxicado. Barcelona: Octaedro, 2006.

SHIVA, Vandana. Guerras por Água. Privatização, poluição e lucro. São Paulo: Radical livros, 2006.

TOURAINE, Alain. Critica a Modernidade. 7. Ed. Petrópolis: Vozes, 2002. 